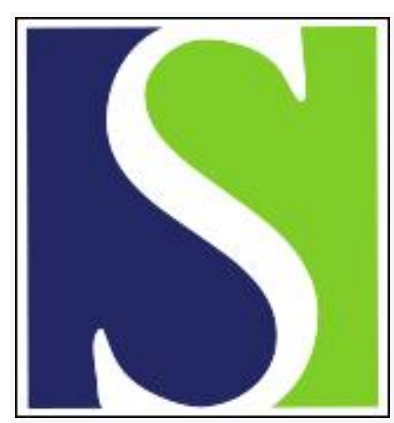

Scand J Work Environ Health 1997;23(1):15-23

https://doi.org/10.5271/sjweh.173

Issue date: Feb 1997

\title{
Mortality of Italian lead smelter workers
}

by Cocco P, Hua F, Boffetta P, Carta P, Flore C, Flore V, Onnis A, Picchiri GF, Colin D

Key terms: cancer mortality; epidemiology; kidney cancer; lead; occupational cohort; renal failure

This article in PubMed: www.ncbi.nlm.nih.gov/pubmed/9098907

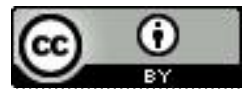




\title{
Mortality of Italian lead smelter workers
}

\author{
by Pierluigi Cocco, MD, ${ }^{1}$ Fu Hua, MD, $, 2,3$ Paolo Boffetta, MD, ${ }^{3}$ Plinio Carta, MD, ${ }^{1}$ Costantino Flore, MD, ${ }^{1}$ \\ Valeria Flore, $S c D,{ }^{4}$ Antonio Onnis, MD, ${ }^{5}$ Gian Franco Picchiri, MD, ${ }^{6}$ Didier Colin ${ }^{3}$
}

\begin{abstract}
Cocco P, Hua F, Boffetta P, Carta P, Flore C, Flore V, Onnis A, Picchiri GF, Colin D. Mortality of Italian lead smelter workers. Scand J Work Environ Health 1997;23(1):15-23.

Objectives The purpose of this study was to evaluate the health consequences of employment in the leadsmelting industry.

Methods A mortality study of 1388 workers and laborers in production and maintenance departments was conducted in an Italian lead-smelting plant. The vital status of cohort members was determined from 1950 to 1992. Standardized mortality ratios were calculated for specific causes of death on the basis of national and regional reference rates. The relative risk for selected causes of death was also modeled as a function of age, calendar period, latency, and duration of employment with Poisson regression analysis.

Results A significant 4.5-fold excess mortality from pneumoconiosis and other diseases of the respiratory system was observed, but the risk of pneumoconiosis did not show a significant trend by duration of employment. Mortality from all cancers, stomach cancer, and lung cancer was lower than expected. The standardized mortality ratios for genitourinary diseases and kidney cancer were not significantly elevated, but the Poisson regression analysis showed that both risks increased significantly by duration of employment.

Conclusions These findings provide limited evidence that long-term employment in lead-smelting plants increases the risk of genitourinary diseases and kidney cancer. The observed increase in mortality from pneumoconiosis and other diseases of the respiratory system was more likely related to silica exposure in other workplaces. No excess risk of stomach cancer and lung cancer was observed in this cohort.
\end{abstract}

Key terms cancer mortality, epidemiology, kidney cancer, lead, renal failure, occupational cohort.

Chronic effects of lead on the hematopoietic system, the central and peripheral nervous system, the digestive system, and the urinary system are well known (1). Whether lead also causes cancer among humans is still uncertain; cancer sites for which an association has been suggested include the lung, the kidney, and the stomach (2). The International Agency for Research on Cancer (IARC) classifies lead and its inorganic compounds as possible human carcinogens on the basis of sufficient evidence from studies on experimental animals (3). The interpretation of epidemiologic results concerning lead-exposed workers is often limited by the co-occurrence of exposure to well-known carcinogens, such as cadmium or arsenic, by an insufficient evaluation of confounders, and by a lack of statistical power (2).

Lead smelter workers have historically experienced the heaviest exposure to the metal. In more recent years, efforts to reduce the concentration of lead in the work environment and to conduct strict biomonitoring of individual contamination have proved effective in sharply reducing the number of cases of acute lead poisoning in lead-smelting plants. However, past high-level exposures may have caused persistent deposits of lead in the bone tissue of exposed workers, from which it may be slowly released to generate prolonged exposure for the internal organs,

Istituto di Medicina del Lavoro (Institute Occupational Medicine), Universita' di Cagliari, Cagliari, Italy.

Department of Epidemiology, Department of Preventive Medicine, Shanghai Medical University, Shanghai, Peoples' Republic of China.

3 Unit of Analytical Epidemiology, International Agency for Research on Cancer, Lyon, France.

4 Dipartimento di Matematica (Department of Mathematics), Universita' di Cagliari, Italy.

5 Servizio di Igiene Pubblica (Department of Public Health), S Gavino Monreale, Cagliari, Italy.

6 Servizio di Medicina Generale (Department of Family Medicine), Sanluri, Cagliari, Italy.

Reprint requests to: Dr Pierluigi Cocco, Istituto di Medicina del Lavoro, Universita' di Cagliari, via San Giorgio 12, 09124 Cagliari, Italy, e-mail: coccop@ipacs.unica.it 
The present study was designed to evaluate causespecific mortality among workers of a lead-smelting plant located in southern Sardinia, Italy.

\section{Methods}

The plant started operation on 10 June 1932 with a potential lead production of $12000 \mathrm{t}$ a year by processing the galena (lead sulfide) ore extracted from a nearby lead and zinc mine owned by the same company. Galena, ferrous mineral, and siliceous material were milled, mixed, and then roasted in Dwight-Lloyd desulfurers to form an agglomerate that was subsequently crushed and mixed with coke and recycled wastes to feed the wind oven in the foundry. The high temperature within the oven separated gases (nitrogen oxides, carbon monoxide, and sulfur dioxide) from wastes (ferrous oxide, silicon dioxide, calcium oxide, and small amounts of lead, copper and silver) and melted lead. Lead was then refined by a thermal process, which removed arsenic and antimony oxides. Copper sulfide and silver were also removed by adding zinc and potassium nitrate, and bismuth was separated by adding calcium and magnesium. In $1938-1939$ the production capacity was tripled, and in 1941 a copper recovery system was started. A system for controlling dust emissions within the work areas was effective, but no information is available on changes in emission control in the work environment. The operations were interrupted in 1943-1945 because of World War II. In 1948 the electrolytic refining of silver and the manufacturing of bullets with a lead-antimony alloy were added, followed in the early 1950 s by the electrolytic refining of lead. The lead refining consisted of a series of cells, each with 24 cathodes (thin, pure lead layers) and 25 anodes (decuperized lead from the foundry mixed with used anodes, melted and then casted) in a fluorosilicic bath. After the treatment, the pure lead cathodes were washed with soda, melted and cast in forms. At that time the total work force was 555 employees (4). The lead smelting plant is still active, although both the number of employees and the production have considerably diminished over the years.

\section{Industrial hygiene data}

In 1977-1978, during an industrial hygiene survey conducted by the Institute of Occupational Medicine of the University of Cagliari (unpublished report), 44 measurements of total dust concentration were performed with stationary samplers. The arithmetic mean was 1.25 (SD 1.34) $\mathrm{mg} / \mathrm{m}^{3}$ over all the work areas; the mean concentration of total dust by work area varied from 0.3 to $2.5 \mathrm{mg} / \mathrm{m}^{3}$. The average area respirable dust concentration was 0.47 (SD 0.33 ) $\mathrm{mg} / \mathrm{m}^{3}$ (based on 155 measure- ments) and varied from 0.1 to $1.2 \mathrm{mg} / \mathrm{m}^{3}$ by work area, while the mean personal concentration of respirable dust was 0.76 (SD 0.62) $\mathrm{mg} / \mathrm{m}^{3}$ (based on 107 measurements) and varied from 0.2 to $1.4 \mathrm{mg} / \mathrm{m}^{3}$ by work area. The percentage of silica in the foundry materials was reported to be around $20 \%$ (4), a level which suggests that exposure to silica may have been relevant in some work areas of the smelting plant. However, no data on the silica percentage of the total or respirable dust level were available, and therefore it was impossible to calculate the exposure to silica. The lead concentration of respirable dust as measured by personal samplers, had a wide range of values (from 1 to $1650 \mu \mathrm{g} / \mathrm{m}^{3}$, with a geometric mean for all work areas of 47.6 (geometric SD 4.90; range by work area $3.6-267) \mu \mathrm{g} / \mathrm{m}^{3}$. The highest respirable dust and lead concentrations were measured by personal samplers in the agglomeration area (respirable dust up to $2.71 \mathrm{mg} / \mathrm{m}^{3}$, lead up to $1650 \mu \mathrm{g} / \mathrm{m}^{3}$ ) and in the foundry (respirable dust up to $2.19 \mathrm{mg} / \mathrm{m}^{3}$; lead up to 209 $\left.\mu \mathrm{g} / \mathrm{m}^{3}\right)$. A measurable exposure to cadmium occurred in the agglomeration area and in the foundry, and it was observed by personal sampling also among the mechanics, who provided maintenance all over the plant. The personal sampler measurements of cadmium in respirable dust were below the detection limit $\left[1 \mu \mathrm{g} / \mathrm{m}^{3}\right.$ in $23 \%$ of the samples ( 9 of 39) and below $10 \mu \mathrm{g} / \mathrm{m}^{3}$ in $72 \%(28$ of 39)]. The two highest measurements were $20 \mu \mathrm{g} / \mathrm{m}^{3}$ for a mechanic and $180 \mu \mathrm{g} / \mathrm{m}^{3}$ for an agglomeration area worker. The levels of arsenic were below the detection limit $\left(1 \mu \mathrm{g} / \mathrm{m}^{3}\right)$ in $96 \%$ of the samples (23 of 24 ), with a reading of $3 \mu \mathrm{g} / \mathrm{m}^{3}$ in the agglomeration area. These measurements are likely to approximate more recent periods of exposure, while exposures in earlier years may have been higher, because of higher production levels and the use of thermal refining instead of electrolytic refining for lead. The unavailability of exposure measurements for earlier periods, the large variation of exposure levels across work areas, and the incompleteness of the job definition $(26 \%$ of the cohort members were classified simply as laborers, and only the information about working in production or maintenance, but not the specific area of the plant, was mentioned for the rest of the cohort) prevented the use of environmental data to construct a cumulative exposure measure incorporating changes across work areas and time. Therefore, duration of employment in production and maintenance jobs was used as a surrogate for cumulative dose.

\section{Definition of the cohort}

A list was retrieved from the company rosters including all employees of the plant hired between 10 June 1932 and 31 July 1971, when the plant changed ownership. Only very few women worked at the smelting plant, and none of them worked in exposed jobs. Therefore, the eligible cohort members were men with at least 12 con- 
secutive months of employment $(\mathrm{N}=1601)$. Table 1 shows the number of subjects excluded from the study according to the criteria for exclusion, and the number of subjects who entered the cohort by vital status at the end of the follow-up. One hundred and six subjects (6.6\%) could not be identified after an extensive search of the communal registrations of birth and the national computerized archives of the Social Security Administration (INPS); for 68 of these persons the last date of employment preceded the start of follow-up, and therefore they were excluded from the study. The other 38 subjects contributed to follow-up until the end of employment, which corresponded to the last date of known vital status. Forty-nine subjects who died before 1 January 1950 were not included in the cohort either. Of the remaining 1484 eligible cohort members, $96(6.5 \%)$ worked only in unexposed jobs, such as accounting, office cleaning, and security, and they were excluded from the cohort. Therefore, 1388 men comprised the cohort. Their vital status was followed from 1 January 1950, or 12 months after the date of hiring, whichever was later, through 31 December 1992, since, for this period, reference rates of the Italian male population were available from the mortality data base of the World Health Organization. They included 740 subjects employed in production areas, 463 subjects employed in maintenance departments, and 358 laborers with no other indication (subjects with multiple jobs included in each subgroup when there were more than just one). Vital status was unknown only for the aforementioned 38 unidentified subjects. Thus the search was $97.3 \%$ successful (1350 of 1388). Fifty-five percent of the cohort members (771 of 1388) had died by the end of the follow-up. Death certificates were available for $96 \%$ of the deceased men (739 of 771). The vital status of the unexposed group $(\mathrm{N}=96)$ was also followed; only 37 deaths (38.5\%) occurred among these workers. The underlying causes of death were coded by an expert nosologist using the 9th revision of the International Classification of Diseases (ICD) (5).

\section{Statistical methods}

Expected deaths were derived by applying the mortality rates of the Italian male population specific by 5 -year age groups and calendar years between 1950-1992 to the appropriate age and time categories of person-years among the cohort members. The mortality rates of the Sardinian male population were available only from 1970 on. We extended the time backwards until 1965 for these rates and repeated the calculation of expected deaths based on these figures. Standardized mortality ratios (SMR) and their 95\% confidence intervals (95\% Cl) were calculated for the total cohort and various subcohorts with the PERSONYEARS computer program (6). The SMR values derived from applying national and regional mortality rates were used to determine the ex-
Table 1. Definition of the cohort and number of subjects by vital status at the end of follow-up.

\begin{tabular}{lr}
\hline Cohort & N \\
\hline Total subjects & 1601 \\
Not identified & 68 \\
Died before start of follow-up & 49 \\
Unexposed (administrative staff, guards, & \\
cleaning personnel) & 96 \\
Entered the cohort & 1388 \\
Alive & 579 \\
Lost during follow-up & 38 \\
Dead & 771 \\
With death certificate & 739 \\
Without death certificate & 32 \\
\hline
\end{tabular}

tent to which the departures from expectation were explained by geographic variation in mortality rates. The relative risk for selected causes of death was explored in a series of Poisson regression models as a function of age, calendar period, latency, and duration of employment using the GLIM (general linear interactive modeling) system. The statistical significance of the trends was tested with the likelihood ratio test for trend obtained with maximum likelihood fitting (7).

\section{Results}

The mean age at first employment was 30.4 (SD 9.4) years. Seventy-five percent (1040 of 1388) of the cohort was hired before 1950. The duration of employment was 5 years or less for $51 \%$ (708 of 1388) of the cohort, while $29 \%$ (401 of 1388) were employed 11 years or more and $11 \%$ (153 of 1388 ) for 21 years or more. Overall, 41372 person-years were accumulated.

The deaths from all causes, all malignant neoplasms, diseases of the nervous system, cardiovascular diseases, and digestive diseases were fewer than expected when compared with the national mortality figures (table 2 ). When expectation was based on regional mortality figures, the all causes mortality showed a $5 \%$ increase of borderline significance, and the SMR values for all malignant neoplasms, cardiovascular diseases, and digestive diseases became closer to unity, a finding indicating a geographic effect on the observed decreases (table 3). Regional mortality rates were not available in computerized form for diseases of the nervous system. Mortality from nonmalignant respiratory diseases was above expectation when compared with both the national and regional rates, due to a 4.5 -fold increase in mortality from pneumoconiosis and other diseases of the respiratory system (ICD codes 500-508.9 and 510-519.9). Fifty-three of these deaths (95\%) were due to pneumoconiosis. Although pneumoconiosis-specific reference mortality rates were not available, the observed excess 
Table 2. Mortality by cause among the lead smelter workers during 1950-1992. The expected deaths were derived from the national mortality rates. (SMR = standardized mortality ratio, $95 \% \mathrm{Cl}=95 \%$ confidence interval)

\begin{tabular}{|c|c|c|c|c|}
\hline Cause of death ${ }^{a}$ & Observed & Expected & SMR & $95 \% \mathrm{Cl}$ \\
\hline All causes $(001-999.9)$ & 771 & 871.1 & 89 & $82-95$ \\
\hline Infectious diseases $(001-139.8)$ & 20 & 16.3 & 123 & $75-190$ \\
\hline Pulmonary tuberculosis $(011-011.9)$ & 14 & 9.5 & 148 & $81-248$ \\
\hline All malignant neoplasms $(140-208.9)$ & 149 & 215.7 & 69 & $58-81$ \\
\hline Digestive organs $(150-159.9)$ & 57 & 91.9 & 62 & $48-81$ \\
\hline $\begin{array}{l}\text { Stomach }(151-151.9) \\
\text { Liver and biliary tract }(155-156.9) \\
\text { Pancreas }(157-157.9)\end{array}$ & $\begin{array}{r}17 \\
16 \\
7\end{array}$ & $\begin{array}{r}34.4 \\
10.1 \\
7.1\end{array}$ & $\begin{array}{r}49 \\
158 \\
99\end{array}$ & $\begin{array}{l}29-79 \\
90-256 \\
40-205\end{array}$ \\
\hline $\begin{array}{l}\text { Respiratory organs }(160-165.9) \\
\text { Trachea, bronchus and lung }(162-162.9) \\
\text { Prostate }(185) \\
\text { Bladder }(188-188.9) \\
\text { Kidney }(189-189.9) \\
\text { Brain }(191-191.9) \\
\text { Lymphatic and hemopoietic tissue }(200-208.9)\end{array}$ & $\begin{array}{r}37 \\
35 \\
11 \\
13 \\
5 \\
4 \\
10\end{array}$ & $\begin{array}{r}66.0 \\
56.4 \\
14.5 \\
10.3 \\
3.5 \\
3.2 \\
13.0\end{array}$ & $\begin{array}{r}56 \\
62 \\
76 \\
126 \\
142 \\
125 \\
77\end{array}$ & $\begin{array}{l}40-77 \\
43-86 \\
38-136 \\
67-216 \\
46-333 \\
34-319 \\
37-141\end{array}$ \\
\hline $\begin{array}{l}\text { Benign neoplasms and neoplasms of } \\
\text { unspecified nature }(210-239.9)\end{array}$ & 3 & 4.3 & 70 & $14-203$ \\
\hline Nervous system diseases $(320-359.9)$ & 13 & 35.8 & 36 & $19-62$ \\
\hline Cardiovascular diseases $(390-459.9)$ & 251 & 356.1 & 70 & $62-80$ \\
\hline $\begin{array}{l}\text { Ischemic heart disease }(410-414.9) \\
\text { Cerebrovascular diseases }(430-438)\end{array}$ & $\begin{array}{r}49 \\
105\end{array}$ & $\begin{array}{l}145.5 \\
111.0\end{array}$ & $\begin{array}{l}34 \\
95\end{array}$ & $\begin{array}{l}25-45 \\
77-115\end{array}$ \\
\hline Respiratory system diseases $(460-519.9)$ & 97 & 75.8 & 128 & $104-156$ \\
\hline $\begin{array}{l}\text { Pneumoconiosis \& other diseases } \\
\text { of the respiratory system }(500-508.9)\end{array}$ & 56 & 12.5 & 447 & $337-580$ \\
\hline Digestive system diseases $(520-579.9)$ & 47 & 63.5 & 74 & $54-98$ \\
\hline Liver cirrhosis $(571-571.9)$ & 23 & 32.5 & 71 & $45-106$ \\
\hline Genitourinary system diseases $(580-608.9)$ & 21 & 16.7 & 126 & $78-192$ \\
\hline III-defined conditions (780-799.9) & 70 & 17.0 & 411 & $320-519$ \\
\hline External causes $(800-999.9)$ & 54 & 44.3 & 122 & $91-159$ \\
\hline
\end{tabular}

a Code of the International Classification of Diseases ( $9^{\text {th }}$ revision) in parentheses.

Table 3. Mortality by cause among the lead smelter workers during 1965-1992. The expected deaths were derived from the regional mortality rates. (SMR $=$ standardized mortality ratio, $95 \% \mathrm{Cl}=95 \%$ confidence interval)

\begin{tabular}{|c|c|c|c|c|}
\hline Cause of deatha & Observed & Expected & SMR & $95 \% \mathrm{Cl}$ \\
\hline All causes $(001-999.9)$ & 636 & 603.2 & 105 & $97-114$ \\
\hline Infectious diseases $(001-139.8)$ & 5 & 6.4 & 78 & $25-182$ \\
\hline Pulmonary tuberculosis $(011-011.9)$ & 3 & 3.9 & 78 & $16-227$ \\
\hline All malignant neoplasms $(140-208.9)$ & 132 & 142.4 & 93 & $78-110$ \\
\hline Digestive organs (150-159.9) & 48 & 50.6 & 95 & $70-126$ \\
\hline $\begin{array}{l}\text { Stomach }(151-151.9) \\
\text { Liver and biliary tract }(155-156.9) \\
\text { Pancreas }(157-157.9)\end{array}$ & $\begin{array}{r}14 \\
13 \\
7\end{array}$ & $\begin{array}{r}14.5 \\
12.2 \\
7.0\end{array}$ & $\begin{array}{r}97 \\
107 \\
100\end{array}$ & $\begin{array}{l}53-162 \\
57-182 \\
40-206\end{array}$ \\
\hline $\begin{array}{l}\text { Respiratory organs (160-165.9) } \\
\text { Trachea, bronchus and lung }(162-162.9) \\
\text { Prostate }(185) \\
\text { Bladder }(188-188.9) \\
\text { Kidney (189-189.9) } \\
\text { Brain (191-191.9) } \\
\text { Lymphatic and hemopoietic tissue }(200-208.9)\end{array}$ & $\begin{array}{r}33 \\
31 \\
10 \\
12 \\
4 \\
4 \\
9\end{array}$ & $\begin{array}{r}43.1 \\
37.9 \\
10.6 \\
8.3 \\
2.3 \\
1.8 \\
9.2\end{array}$ & $\begin{array}{r}75 \\
82 \\
94 \\
145 \\
175 \\
217 \\
98\end{array}$ & $\begin{array}{l}52-105 \\
56-116 \\
45-174 \\
75-253 \\
48-449 \\
57-557 \\
45-187\end{array}$ \\
\hline Cardiovascular diseases (390—459.9) & 220 & 304.7 & 84 & $74-96$ \\
\hline $\begin{array}{l}\text { Ischemic heart disease }(410-414.9) \\
\text { Cerebrovascular diseases }(430-438)\end{array}$ & $\begin{array}{l}44 \\
93\end{array}$ & $\begin{array}{l}87.7 \\
76.2\end{array}$ & $\begin{array}{r}50 \\
122\end{array}$ & $\begin{array}{l}36-67 \\
98-149\end{array}$ \\
\hline Respiratory system diseases $(460-519.9)$ & 90 & 59.0 & 153 & $123-188$ \\
\hline Digestive system diseases $(520-579.9)$ & 35 & 47.8 & 73 & $51-102$ \\
\hline Liver cirrhosis $(571-571.9)$ & 20 & 29.8 & 67 & $41-104$ \\
\hline Genitourinary system diseases (580-608.9) & 14 & 10.3 & 135 & $74-227$ \\
\hline III-defined conditions (780-799.9) & 54 & 13.8 & 390 & $293-502$ \\
\hline External causes $(800-999.9)$ & 38 & 30.5 & 124 & $88-171$ \\
\hline
\end{tabular}

a Code of the International Classification of Diseases ( $9^{\text {th }}$ revision) in parentheses. 
was probably related to an increase in mortality from pneumoconiosis. Nonmalignant diseases of the genitourinary system and deaths from external causes, including 12 deaths from chronic lead poisoning (saturnism), showed small excesses $(22-26 \%$ based on national rates). The average duration of employment in exposed jobs among the 12 workers who died from saturnism was 20.5 (median 20, SD 7.3) years. Seven of these workers had multiple jobs: 8 of 12 had worked in the maintenance department, 6 of 12 had worked in production areas, and 7 of 12 were only defined as laborers. The proportion of deaths from saturnism was higher among laborers $(3.23 \% ; 7$ of 217$)$ and maintenance workers $(3.15 \% ; 8$ of 254$)$, than among the production workers $(1.47 \%, 6$ of 407$)$. The 70 deaths from ill-defined causes among the exposed workers were 4 times more than expected from either national or regional mortality figures. Nineteen of these deaths were classified as due to senility; that number alone was greater than expected for all ill-defined conditions combined. The average duration of employment in exposed jobs among the 19 men who died from senility was 5.8 (median 3, SD 6.4) years, and only 4 of 19 worked 10 years or more. Only 2 of these workers had 2 jobs in their work history at the smelting plant, and all the others had only 1 job. Eight of them were laborers, 6 of whom worked only for 1 year; 7 worked in production areas (duration range 1 18 years); and 6 in the maintenance department (duration range $2-16$ years).

According to the national mortality figures, stomach cancer and lung cancer were significantly decreased, while deaths from cancer of the liver and biliary tract, bladder cancer, and kidney cancer were nonsignificantly above expectation (table 2). When expectation was based on regional mortality rates, the SMR was closer to unity and not statistically significant for stomach cancer, lung cancer, and liver and biliary tract cancer, while increases were observed for bladder cancer, kidney cancer, and brain cancer (table 3). No excess deaths from prostate cancer, and neoplasms of the lymphatic and hemopoietic tissue were observed when compared with both reference rates.

The SMR values did not show differences between the production workers, maintenance workers, and lab- orers, with the remarkable exception of kidney cancer, genitourinary diseases, and deaths from external causes (table 4). Kidney cancer was increased only among the laborers; genitourinary diseases were increased among the maintenance workers and among the laborers, but not among the production workers; and deaths from external causes, which included saturnism, were mostly increased among the maintenance workers and laborers.

Using national mortality figures, SMR values were also calculated for subcohorts defined by whether employed before 1946 or from 1946 on, when production resumed after the end of World War II, and a few technological changes and new production lines were introduced. The SMR for pneumoconiosis and other diseases of the respiratory system was higher among the workers first exposed in 1946 or later, while all deaths from genitourinary diseases and 4 of 5 observed deaths from kidney cancer occurred among workers first exposed before 1946, with the greatest excess among workers employed 21 years or more for both diseases (kidney cancer: SMR 526, 95\% CI 64--1901, based on 2 deaths; genitourinary diseases: SMR 301, 95\% CI 98-703, based on 5 deaths) (not shown in the tables).

The risk from saturnism, pneumoconiosis, genitourinary diseases, renal failure, lung cancer and kidney cancer were modeled in a Poisson regression as a function of age, calendar period, latency, and duration of employment (tables 5 and 6) with the cohort members employed $1-5$ years in production and maintenance jobs as the base-line reference. In the regression models for renal failure and kidney cancer, the base-line reference was extended to include cohort members employed 1 10 years, since no such deaths were observed in the $1-$ 5 years of employment category. Latency did not improve the fitness of the models significantly, but the lowest category was set at 25 years or lower for genitourinary diseases and 40 years or lower for kidney cancer and renal failure. Risk of saturnism increased sharply with duration of employment, and the trend was highly significant and therefore indicated that the duration of employment was a reasonable surrogate for exposure to lead in this cohort. The risk of pneumoconiosis and lung cancer increased slightly among smelter workers employed 6-10 years and $11-20$ years, but both risks

Table 4. Mortality from kidney cancer, genitourinary diseases, and deaths from external causes among the production workers, maintenance workers, and laborers. The expected deaths were derived from the national mortality rates. (SMR = standardized mortality, $95 \% \mathrm{Cl}=95 \%$ confidence interval)

\begin{tabular}{|c|c|c|c|c|c|c|c|c|c|}
\hline \multirow[t]{2}{*}{ Subcohort } & \multicolumn{3}{|c|}{ Kidney cancer } & \multicolumn{3}{|c|}{ Genitourinary diseases } & \multicolumn{3}{|c|}{ Accidents and poisoning } \\
\hline & $\begin{array}{l}\text { Observed } \\
\text { deaths }\end{array}$ & SMR & $95 \% \mathrm{Cl}$ & $\begin{array}{c}\text { Observed } \\
\text { deaths }\end{array}$ & SMR & $95 \% \mathrm{Cl}$ & $\begin{array}{l}\text { Observed } \\
\text { deaths }\end{array}$ & SMR & $95 \% \mathrm{Cl}$ \\
\hline $\begin{array}{l}\text { Production } \\
\text { Maintenance } \\
\text { Laborers }\end{array}$ & $\begin{array}{l}2 \\
1 \\
3\end{array}$ & $\begin{array}{r}104 \\
88 \\
337\end{array}$ & $\begin{array}{r}13-374 \\
2-489 \\
70-985\end{array}$ & $\begin{array}{l}7 \\
9 \\
8\end{array}$ & $\begin{array}{r}81 \\
158 \\
186\end{array}$ & $\begin{array}{l}33-168 \\
72-300 \\
80-367\end{array}$ & $\begin{array}{l}28 \\
24 \\
19\end{array}$ & $\begin{array}{l}117 \\
162 \\
171\end{array}$ & $\begin{array}{r}78-170 \\
104-241 \\
103-267\end{array}$ \\
\hline
\end{tabular}


Table 5. Relative risk (RR) for saturnism, pneumoconiosis, and lung cancer by the years of employment of the lead smelter workers. $(95 \% \mathrm{Cl}=95 \%$ confidence interval)

\begin{tabular}{|c|c|c|c|c|c|c|c|c|c|}
\hline \multirow{2}{*}{$\begin{array}{l}\text { Duration of } \\
\text { exposure }\end{array}$} & \multicolumn{3}{|c|}{ Saturnisma $^{a}$} & \multicolumn{3}{|c|}{ Pneumoconiosis } & \multicolumn{3}{|c|}{ Lung cancer } \\
\hline & $\begin{array}{c}\text { Observed } \\
\text { cases }\end{array}$ & $\mathrm{RR}$ & $95 \% \mathrm{Cl}$ & $\begin{array}{c}\text { Observed } \\
\text { cases }\end{array}$ & $\mathrm{RR}$ & $95 \% \mathrm{Cl}$ & $\begin{array}{l}\text { Observed } \\
\text { cases }\end{array}$ & $\mathrm{RR}$ & $95 \% \mathrm{Cl}$ \\
\hline $1-5$ years & \multirow{2}{*}{1} & \multirow{2}{*}{1.0} & \multirow{2}{*}{-} & 19 & 1.0 & . & 17 & 1.0 & \\
\hline $6-10$ years & & & & 9 & 1.6 & $0.7-3.5$ & 7 & 1.3 & $0.6-3.2$ \\
\hline $11-20$ years & 6 & 19.2 & $2.3-159$ & 13 & 1.7 & $0.9-3.5$ & 9 & 1.3 & $0.6-3.0$ \\
\hline$\geq 21$ years & 5 & 38.5 & $4.4-340$ & 5 & 0.9 & $0.3-2.5$ & 2 & 0.4 & $0.1-1.7$ \\
\hline $\begin{array}{l}\text { Test for } \\
\text { trend (P-value) }\end{array}$ & \multicolumn{3}{|c|}{0.0000} & \multicolumn{3}{|c|}{0.497} & \multicolumn{3}{|c|}{0.596} \\
\hline
\end{tabular}

a Base-line reference category set at $1-10$ years of employment.

Table 6. Relative risk (RR) for genitourinary disease, renal failure, and kidney cancer by years of exposure of the lead smelter workers. ( $95 \% \mathrm{Cl}=95 \%$ confidence interval)

\begin{tabular}{|c|c|c|c|c|c|c|c|c|c|}
\hline \multirow{2}{*}{$\begin{array}{l}\text { Duration of } \\
\text { exposure }\end{array}$} & \multicolumn{3}{|c|}{ Genitourinary disease } & \multicolumn{3}{|c|}{ Renal failure ${ }^{a}$} & \multicolumn{3}{|c|}{ Kidney cancer } \\
\hline & $\begin{array}{l}\text { Observed } \\
\text { cases }\end{array}$ & $\mathrm{RR}$ & $95 \% \mathrm{Cl}$ & $\begin{array}{c}\text { Observed } \\
\text { cases }\end{array}$ & $\mathrm{RR}$ & $95 \% \mathrm{Cl}$ & $\begin{array}{c}\text { Observed } \\
\text { cases }\end{array}$ & RR & $95 \% \mathrm{Cl}$ \\
\hline$\leq 5$ years & 4 & 1.0 & . & & & & & & \\
\hline $6-10$ years & 5 & 4.1 & $1.1-15.2$ & 5 & 1.0 & & 1 & 1.0 & . \\
\hline $11-20$ years & 7 & 5.0 & $1.5-17.3$ & 3 & 2.1 & $0.5-9.0$ & 2 & 6.7 & $0.6-73.5$ \\
\hline$\geq 21$ years & 5 & 6.6 & $1.7-26.1$ & 3 & 3.5 & $0.8-15.1$ & 2 & 10.9 & $1.0-121$ \\
\hline $\begin{array}{l}\text { Test for } \\
\text { trend (P-value) }\end{array}$ & & 0.002 & & & 0.094 & & & 0.036 & \\
\hline
\end{tabular}

a Base-line reference category set at $1-10$ years of employment.

were lower than unity for the workers employed 21 years or more (table 5). The risk of genitourinary diseases and kidney cancer showed a significant increase with duration of employment up to 6.6-fold and almost 11-fold, respectively, among the smelter workers employed 21 years or more. Both trends were statistically significant (table 6). Regression models were also explored using the unexposed group as the reference category and including it in the base-line reference together with the cohort members exposed $1-5$ or $1-10$ years. The pattern of increasing risk with duration of exposure for genitourinary diseases and kidney cancer was substantially confirmed, although the risks were smaller due to the excess rates of genitourinary diseases and kidney cancer also among the unexposed group, as compared with that of both the reference populations. In addition, attributing the expected number of deaths derived from the national mortality rates of kidney cancer to the $1-5$ years category of duration and using this category as the reference confirmed the monotonic increase in kidney cancer risk by duration of employment. Adjusting by age and calendar year in the Poisson regression reduced the rate ratio for kidney cancer associated with $\geq 21$ years of employment from 16.0 to 10.9 . No substantial change was observed for the other disease risks modeled with the Poisson regression. Renal failure (ICD codes 584-
586) accounted for $52 \%$ (11 of 21) of the deaths from genitourinary diseases. Among these 11 deaths, 1 was classified as due to acute renal failure, 4 as chronic renal failure, and 6 as unspecified renal failure. The relative risk for renal failure also increased with duration of employment, but the risks were apparently smaller than for genitourinary diseases, and the trend was no longer statistically significant. However, since the base-line reference was extended in this analysis to cohort members employed up to 10 years, a direct comparison with the risks of genitourinary diseases would be inappropriate.

All cancers, stomach cancer, and neoplasms of the lymphatic and hemopoietic tissue did not increase either by duration of employment or number of years since first exposure (not shown in the tables). Bladder cancer had the highest SMR for the subjects employed 6-10 years, 41 or more years since first exposure, but the risk did not increase by duration of employment. All deaths from brain cancer occurred among workers employed $\leq 10$ years (not shown in the tables).

\section{Discussion}

The results of this cohort study of lead smelter workers suggest an increase in the risk for genitourinary diseases and possibly kidney cancer. Stomach cancer, lung can- 
cer, prostate cancer, and neoplasms of the lymphatic and hemopoietic tissue did not show any increase. A 4.5-fold excess mortality from pneumoconiosis and other diseases of the respiratory system was also observed, but the risk of pneumoconiosis did not increase by duration of employment. The SMR for pneumoconiosis and other respiratory diseases was highest among workers first exposed in 1946 or later, and elevated SMR values were measured also for short-term workers. Five out of the 11 pneumoconiotic workers who started exposure in 1946 or later were 40 years of age or older when hired, while only 3 of 41 pneumoconiotic workers who started exposure before 1946 were in this age range when hired. It is possible that previous silica exposure in other workplaces, such as a nearby lead and zinc mine owned by the same company, could have contributed to the observed excess of pneumoconiosis among the more recent subcohort. By contrast, higher exposures might have been more likely to have played a role earlier, but complete work histories of the study subjects were not available with which to explore this possibility.

In this study we observed excess deaths from pneumoconiosis, but mortality from lung cancer was not increased. This finding apparently contradicts the epidemiologic evidence supporting an association between silicosis and lung cancer, while evidence is less conclusive for silica itself (8). Misdiagnosis of lung cancer on the death certificates might have prevented the detection of such an association while contributing at the same time to an increase in the SMR for ill-defined causes. However, in an earlier follow-up study of 2 lead and zinc mines located in the vicinity of the smelting plant, we found that lung cancer risk was increased among the miners whose silica exposure and risk of pneumoconiosis were lower, but for whom the levels of radon daughters were measurable, while no excess risk of lung cancer was found among the miners whose silica exposure and the risk of pneumoconiosis were very high, but for whom the radon-daughter levels were negligible (9). On the other hand, in this study, the Poisson regression analysis showed that the risk of pneumoconiosis and lung cancer followed parallel curves by duration of employment, with small increases up to 20 years of employment and a decrease thereafter, when cohort members employed $1-10$ years were used as the internal reference. The results of the present study cannot be used to either support or reject an association between silica, silicosis and lung cancer. It is also possible that a reduced smoking habit, compared with that of both external references, may have contributed to a lower than expected mortality from lung cancer in this cohort, but no data on smoking were available with which to correct the risk estimate for the cohort members.

A significant decrease in mortality from cardiovascular diseases, nervous system diseases, and digestive dis- eases was observed in this cohort. At least, in part, the misdiagnosis and underreporting of degenerative disorders of the central nervous system and cerebrovascular diseases on the death certificate, particularly among elderly cohort members, might have generated the deficit, as a 4-fold excess was found for ill-defined conditions. In fact, the SMR for these three groups of deaths and illdefined causes combined was $81(95 \%$ CI 73-89) when based on national rates.

A recent study reported an association between brain glioma risk and previous high blood lead level (10). We also found an excess risk of brain cancer for our cohort, but the deaths affected only workers exposed less than 10 years. The association between lead exposure and brain cancer is biologically plausible, and it is worth exploring in more detail in future studies of lead smelters.

Because of the incompleteness of the job definition of the cohort members and the unavailability of exposure measurements for earlier periods, the interpretation of these findings is limited by the use of duration of employment as a surrogate for cumulative exposure. However, the sharp increase in risk observed for saturnism, and the long average duration of exposure among the subjects who died from saturnism, suggest that the duration of employment was a reasonable surrogate for exposure to lead in this cohort. Histology data would have also been helpful in the evaluation of the associations, but we did not try to retrieve these data, as a substantial proportion of the deaths had occurred early in the followup period and the effort needed would have probably resulted in a poor success rate.

Due to the unavailability of rates at the regional level for the first half of the follow-up, we used the national male population as the reference for the total period of follow-up and compared these results with those obtained by applying the regional rates to the person-years accumulated along the follow-up period covered by these rates (1965-1992). This comparison allowed an interpretation for the observed significant decreases in the SMR for all causes, all cancers, stomach cancer and lung cancer, and the increase in liver and biliary tract cancer mortality were almost entirely found to be due to regional effects.

As kidney cancer accounts for about $0.4 \%$ of total deaths both at the national and regional level, the small size of the cohort, in spite of the length of follow-up, allowed the observation of only a few deaths from kidney cancer. Therefore, the low statistical power of this study is one cause of concern in the interpretation of the increase in kidney cancer risk observed in this study. However, an association between kidney cancer and exposure to lead is supported by animal studies (3), case reports $(11,12)$, and a recently updated cohort study of lead smelter workers $(13,14)$. Negative results have been reported for battery workers (15) and glass workers (16), 
two occupational groups which usually experience lower exposures to the metal than smelter workers. Results from 6 lead production facilities and 10 battery plants in the United States found excess risks of stomach cancer and lung cancer, both inversely related to the length of employment, and no excess risk of kidney cancer (17). However, only 2 deaths from kidney cancer occurred, and they were among workers in lead smelting, refining, and recycling who had 11-20 years of employment and who started work before 1946 (SMR 800). The mortality from chronic nephritis was also significantly increased, and all deaths from this disease occurred among lead smelters employed $\geq 20$ years (17). An analysis of kidney cancer risk among Finnish workers whose blood lead level was monitored found no association with blood lead levels, although the follow-up period may have been short, and lead smelters, who showed the highest blood lead values, comprised only $2 \%$ of the cohort (18).

Concurrent exposure to cadmium, whose nephrotoxicity is well known (19), has been a major concern in interpretations of increased risks for kidney cancer and renal failure in previous studies (2), and it may have played a role in this cohort as well, as industrial hygiene data were available only for the most recent period of follow-up. However, at the time of the industrial hygiene survey, exposure to cadmium was generally low, with only 1 measurement exceeding the threshold limit value of the American College of Governmental Industrial Hygienists of $50 \mu \mathrm{g} / \mathrm{m}^{3}(20), 23 \%$ being below the detection limit and $72 \%$ ( 28 of 39 ) being below $10 \mu \mathrm{g} / \mathrm{m}^{3}$. Besides, other targets, which could have been affected by cadmium, such as cancer of the lung and prostate cancer (21), were not increased in this study.

Kidney is a target organ for lead toxicity (22), and it provides the main route of excretion of the metal. The damage apparently starts in the proximal tubular lining cells, where lead is extensively taken up by membrane binding and possibly passive transport (19). Soluble proteins bind to lead and mediate its intranuclear transport and chromatin binding. Mitochondria also undergo leadinduced ultrastructural changes (19). These effects seem reversible, but prolonged lead exposure may eventually lead to tubular atrophy and dilation evolving toward peritubular fibrosis. A link between lead nephrotoxicity and kidney cancer in rodents has been suggested by experimental studies showing an evolution of lead nephropathy to renal adenocarcinoma (22). Lead is also a mitogen and has genotoxic properties although only indirectly through the inhibition of enzymes relevant for DNA (deoxyribonucleic acid) synthesis or repair. Both these mechanisms may be important in renal carcinogenesis (22).

Hypertension and central and peripheral neurotoxicity have also been reported as being related to occupational exposure to lead $(1,22)$. In a death certificate study of battery and lead production workers in the
United States, a significant excess risk of death from hypertension was found, but the authors observed that this finding was partially explained by changes in the ICD coding of hypertensive renal disease (17). Although mortality rates from hypertension were not available in our study for calculating expected events, we observed a reduction in mortality from cardiovascular diseases and, particularly, from ischemic heart disease.

Findings of the association between lead exposure and kidney cancer are contradictory across studies. Positive results have typically been seen in studies of lead smelters with long-term exposure to high levels and a long latency period. Further research with sufficient statistical power is required to confirm or reject the hypothesis of an association between occupational lead exposure and kidney cancer, with insights into the putative role of lead-related chronic nephropathy in the development of kidney cancer.

\section{Acknowledgments}

Dr Fu was supported by an IARC research training fellowship. The study was partially supported by a European Commission BIOMED grant (contract no BMH1CT92-1110).

\section{References}

1. Johnstone RT, Miller SE. Occupational diseases and industrial medicine. Philadelphia (PA): Saunders Co, 1960:286-300.

2. Fu H, Boffetta P. Cancer and occupational exposure to inorganic lead compounds: a meta-analysis of published data. Occup Environ Med 1995;52:73-81.

3. International Agency for Research on Cancer (IARC). Some metals and metallic compounds. Lyon: IARC, 1980:325415. IARC monographs on the evaluation of the carcinogenic risk to humans, vol 23.

4. Marini M, Troi G. La fonderia di piombo di S Gavino Monreale [The S Gavino Monreale lead smelting plant]. In: Societa' di Montevecchio. Notizie sull'industria del piombo e dello zinco in Italia [The lead and zinc industry in Italy]. Milano: Societa' Italiana del Piombo e dello Zinco, 1948:571—647.

5. World Health Organization (WHO). International classification of diseases, 1975 revision. Geneva: WHO, 1977.

6. Coleman M, Douglas A, Hermon C, Peto J. Cohort study analysis with a FORTRAN computer program. Int J Epidemiol 1986;15:134-7.

7. Breslow NE, Day NE. Statistical methods in cancer research. Lyon: International Agency for Research on Cancer (IARC), 1987. IARC scientific publication, no 82.

8. McDonald C. Silica, silicosis and lung cancer: an epidemiological update. Appl Occup Environ Hyg 1995;10:1056 - 63.

9. Cocco P, Carta P, Belli S, Picchiri G, Flore MV. Mortality of Sardinian lead and zinc miners: 1960-88. Occup Environ Med 1994;51:674-82. 
10. Anttila A, Heikkila P, Nykyry E, Kauppinen T, Pukkala E, Hernberg $S$, et al. Risk of nervous system cancer among workers exposed to lead. J Occup Environ Health 1996;38: $131-6$.

11. Baker El, Goyer RA, Fowler BA, Khettry U, Bernard DB, Adler S, et al. Occupational lead exposure, nephropathy, and renal cancer. Am J Ind Med 1980;1:139_48.

12. Lilis R. Long-term occupational lead exposure, chronic nephropathy, and renal cancer: a case-report. Am J Ind Med 1981;2: 293-7.

13. Selevan S, Landrigan PJ, Sterm FB, Jones JH. Mortality of lead smelter workers. Am J Epidemiol 1985;122:673-83.

14. Steenland K, Selevan S, Landrigan P. The mortality of lead smelter workers: an update. Am J Public Health 1992;82: $1641-4$

15. Cooper WC, Gaffey WR. Mortality of lead workers. J Occup Med 1975;17:100-7.

16. Sänkilä R, Karjalainen S, Pukkala E, Oksanen H, Hakulinen T, Teppo L, et al. Cancer risk among glass factory workers: an excess of lung cancer? Br J Ind Med 1990;47:815-18.
17. Cooper WC, Wong O, Kheifets L. Mortality among employees of lead battery plants and lead-producing plants, 1947-1980. Scand J Work Environ Health 1985;1 1:331 - 45.

18. Anttila A. Occupational exposure to lead and risk of cancer. Tampere (Finland): University of Tampere, 1994.

19. Fowler BA. Mechanisms of kidney cell injury from metals. Environ Health Perspect 1992;100:57-63.

20. American Conference of Governmental Industrial Hygienists (ACGIH). Cadmium fume - as $\mathrm{Cd}$ documentation of the threshold limit values for substances in workroom air. Cincinnati (OH): ACGIH, 1976:292.

21. International Agency for Research on Cancer (IARC). Beryllium, cadmium, mercury, and exposures in the glass manufacturing industry. Lyon: IARC, 1993:119-237. IARC monographs on the evaluation of the carcinogenic risk to humans, vol 58.

22. Goyer RA. Lead toxicity; current concerns. Environ Health Perspect 1992;100:177-87.

Received for publication: 22 January 1996 